\title{
Analysis of porosity comparison formed on film layer of self-processed copal and alcohol based varnish against manufacture based varnish
}

\author{
Agustina Dewi*, Zulia Hasratiningsih**, Elin Karlina**, Nadia Greviana** \\ *Community Health Centre of Weduai Ministry of Health Republic of Indonesia \\ **Department of Dental Material Science and Technology Faculty of Dentistry Universitas \\ Padjadjaran, Indonesia
}

\begin{abstract}
Introduction: Varnish is one of the dental materials that can be used to protect the pulp. Raw materials for making varnish were easy to be obtained using simple technique and composition. Self-processed varnish which has $40 \mathrm{gr}$ of copal, $50 \mathrm{~mL}$ of $95 \%$ alcohol and $10 \mathrm{~mL}$ of chloroform was produced. When applied, varnish formed a thin film layer which tend to porous. The aim of this study was to analyze the comparison between porosity which formed in film layer of self-processed and factory varnish. Methods: This study was true experimental with 12 third upper molars that had been cut horizontally as specimens and were divided into 2 groups as treated and control groups. First group had 1, 2, 3 and 4 times application of processed varnish as treated sample and second group samples were applied with factory varnish as control sample. Porosity was tested using SEM then its percentage was calculated by comparing the porosity and the tooth area. The data was then tested with t-independent test. Results: The result showed that self-processed varnish obtained larger percentage of porosity. Started at the third application time, both processed and factory varnish showed no porosity. Conclusion: The conclusion of this study was that there is difference between porosity which formed in film layer of self-processed and factory varnish.
\end{abstract}

Keywords: Varnish,copal, Self-processed, factory varnish, porosity

\section{INTRODUCTION}

Protection of dental pulp is necessary for opened dental tubuli and pulp after teeth preparation. ${ }^{1}$ One of the materials used for pulp protector is varnish, with film thickness between 1-40 $\mu \mathrm{m} .^{2-}$ ${ }^{4}$ The thin film layer of varnish is insufficient for protecting against thermal and mechanic elements, but is a sufficient protector against chemical substance. ${ }^{3-7}$
Varnish can reduce the entry of elements that can irritate the pulp from the restoration or cement base used. Varnish can also block the entry of oral fluid by reducing micro leakage thereby reducing the sensitivity of the pulp after the restoration process is completed. In amalgam restorations, varnish can reduce the entry of corrosion products to the dentinal tubules thus reducing tooth discoloration. In addition, varnish is used as coating to protect the restorations from 
dehydration or contact with oral fluids (such as glass ionomer and silicate restorations). ${ }^{3,4,8}$

One of the materials that can be used as raw material of varnish is copal. Copal is easily available on the market as Indonesia is the world's largest producer and exporter of copal since. ${ }^{9}$ Copal is one of Indonesia's export commodities which controls $80 \%$ of the world market and one of the producing regions is Probolinggo. ${ }^{10}$ Other areas in Indonesia that produce copal are Makassar and Pontianak. ${ }^{11}$ The easy-to-obtain raw material of varnish in a relatively simple way and composition based on Grossman ${ }^{12}$ makes it possible to make self-processed varnish.

Varnish is a solution consisting of one or more resins which can be derived from natural or synthetic resins dissolved into organic solvents. ${ }^{3,4,8,13}$ One of the natural gums often used as raw material for making varnish is copal. ${ }^{14}$ Copal is the result of secretion of various trees belonging to the family Pinaceae. Copal is also widely used as raw material for making varnish. Copal contains organic acids, so organic solvents are used to dissolve them. ${ }^{15}$

The organic solvents which can be used for the preparation of varnish are alcohols, ethers, chloroforms, acetone, benzene, toluene, ethyl acetate, and amyl acetate. 4,13,16,17 In this study, alcohol was used as the main solvent. The alcohol used was ethanol with a concentration of $95 \%$. After water, ethanol is the most useful solvent in pharmaceuticals, used as the main solvent for many organic compounds. ${ }^{18}$ Alcohol is relatively safer when compared to other organic solvents. ${ }^{19}$

In the application, varnish is applied with several times of application. In some literature, it is mentioned that varnish is applied with twice to three times of application. ${ }^{3,4,6,21,22}$ This is because the drying of the first film layer may leave small holes or porosity and the second layer will cover the porosity resulting in a more homogeneous layer. ${ }^{3,4,6,14}$

Once applied to the tooth surface, varnish forms film layer immediately after the solvent evaporates. The average solvent takes 8-20 seconds to evaporate. ${ }^{1,14,20}$ The film layer formed is a porous layer, therefore, it takes two to three times of application. ${ }^{3,4,6,13}$ Varnish can be applied to the surface of the tooth using a brush or cotton pledget. ${ }^{4,8,14}$
One particular importance in the application of varnish is the formation of a uniform and unbroken film layer. ${ }^{3,4,6,13}$ This can be obtained by applying a thin layer of varnish with several times of application. This technique is much more effective than a one-time varnish with thick layers. ${ }^{4}$ Based on previous explanations and reasons, a study to analyze the porosity ratio formed on the self-processed varnish and the factory varnish was conducted.

\section{METHODS}

The type of research used was pure experimental with sample of self-processed varnish and factory-made varnish (GC Fuji Varnish). The first procedure is the preparation of a self-processed varnish with a composition of $40 \mathrm{gr}$ of copal, 50 $\mathrm{mL}$ of $95 \%$ alcohol, and $10 \mathrm{~mL}$ of chloroform, by dissolving coagulant that has been mashed into a mixture of alcohol and chloroform and then the result is filtered. Further preparation of dental specimens was conducted by cutting the upper molar of 12 pieces in the transverse direction on the crown to obtain a flat field on the dentin with a thickness of $7 \mathrm{~mm}$. The piece of the tooth was inserted into the decorative resin mold; resin was poured, hardened, and was then polished with fine sandpaper. Then, either self-processed or manufactured varnishes was applied to dental specimens with $1,2,3$, and 4 times polishing frequency on each different tooth and repeated twice on the second polishing frequency. The porosity formed on the film layer was observed using SEM. Materials and instruments used in this study were shown in Figure 1.

\section{RESULTS}

Calculation of porosity percentage was conducted based on existing means, the image proplus software. The porosity percentage of the varnish film layer was obtained from the wide sum of the entire porosity formed by the surface area of the tooth viewed from the photograph using SEM (Scanning Electron Microscope) and multiplied $100 \%$.

The porosity image of the varnish film layer with once to four times applications on the selfprocessing varnish were shown in Figure 2, while 


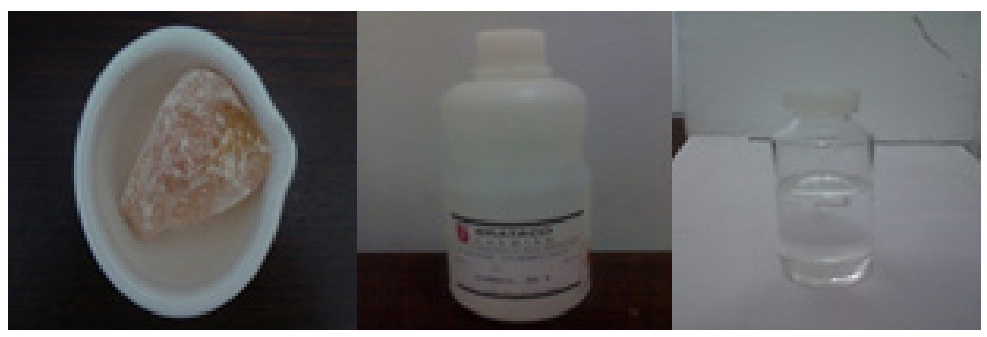

1

2

3

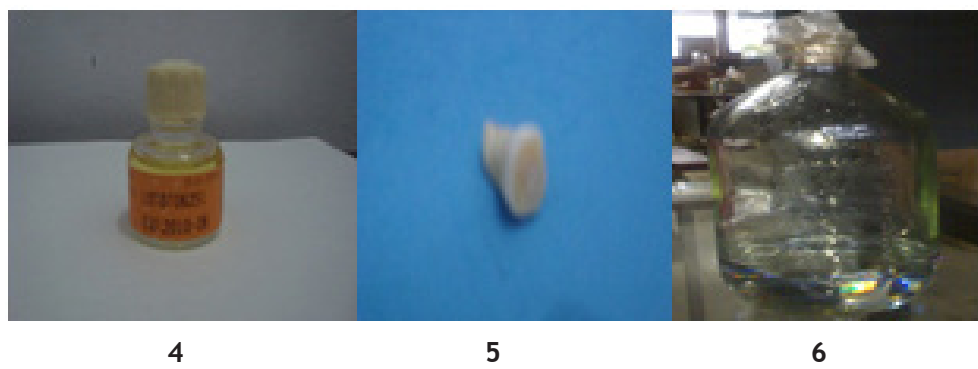

Figure 1. Materials: (1) copal, (2) alcohol 95\%, (3) chloroform, (4) Fabricated varnish (GC Fuji Varnish), (5) Upper third molars (6) decorative resin.

the factory-made varnish application was shown in Figure 3. The result of difference of percentage of porosity which formed at film layer and the influence of self-processed varnish and the fabricated varnish frequency after applying on tooth surface were shown in Table 1.

The percentage of porosity occurring in the self-processed film layer of varnish with single application was $0.402 \%$, while in the factory-made varnish, with the same polishing frequency, the porosity percentage was $0.310 \%$. Self-processed varnish with two times of application showed the porosity percentage of $0.226 \%$, while in the fabricated varnish, the percentage reached $0.157 \%$. For both types of varnishes, no porosity was shown in the film layer on the third and fourth application.

After conducting the research to see the effect of the polishing frequency on the porosity formed on the self-made varnish film layer and the factory-made varnish, the application was repeated twice in both type of varnish respectively. The repetition results were shown in Table 2 .

To perform the statistical calculation, the calculation of the average percentage of porosity of the self- processed varnish and GC Fuji varnish with two times of application can be seen in Table 3 .

The results of statistical calculations indicated that there was no difference between the porosity formed on the film layer of copalbased and alcohol self-processed varnish with factory-made varnish.
Table 1. Porosity percentage on varnish film layer

\begin{tabular}{lcccc}
\hline \multirow{2}{*}{\multicolumn{1}{c}{ Type of Varnish }} & \multicolumn{4}{c}{ Application } \\
\cline { 2 - 5 } & I & II & III & IV \\
\hline Self-processed varnish & $0.402 \%$ & $0.226 \%$ & $0 \%$ & $0 \%$ \\
Fabricated varnish & $0.310 \%$ & $0.157 \%$ & $0 \%$ & $0 \%$ \\
\hline
\end{tabular}

Table 2. Porosity Percentage on film layer of self-processed varnish and fabricated farnish on two times of applications

\begin{tabular}{cc}
\hline Self-processed varnish & Fabricated varnish \\
\hline $0.226 \%$ & $0.157 \%$ \\
$0.140 \%$ & $0.123 \%$ \\
\hline $0.265 \%$ & $0.104 \%$ \\
\hline
\end{tabular}

Table 3. Average Percentage of Porosity on a Self-processed Varnish Film Layer and fabricated varnish at two times of application

\begin{tabular}{lccc}
\hline \multicolumn{1}{c}{ Type of varnish } & $\bar{x}$ & \pm & $\mathrm{S}$ \\
\hline Self-processed varnish & $0.210 \%$ & \pm & $0.064 \%$ \\
Fabricated varnish & $0.128 \%$ & \pm & $0.027 \%$ \\
\hline
\end{tabular}

\section{DISCUSSION}

The self-processed varnish was composed of 40 grams of copal, $50 \mathrm{~mL}$ of $95 \%$ alcohol, and $10 \mathrm{~mL}$ of chloroform. This composition was taken based on Grossman with modification and based on the preformulated results in preliminary study. Initial varnish preparations were made with $70 \%$ alcohol solvent, which once applied to teeth, it resulted 


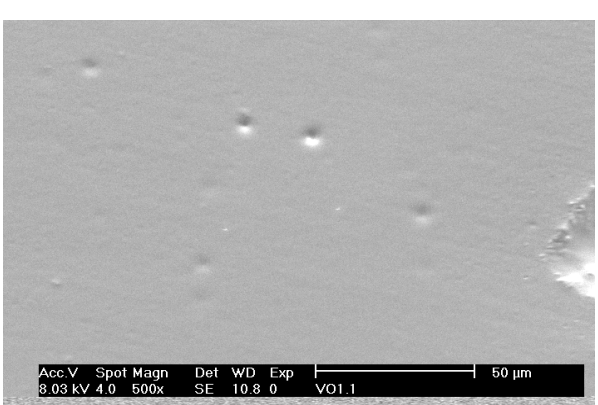

A

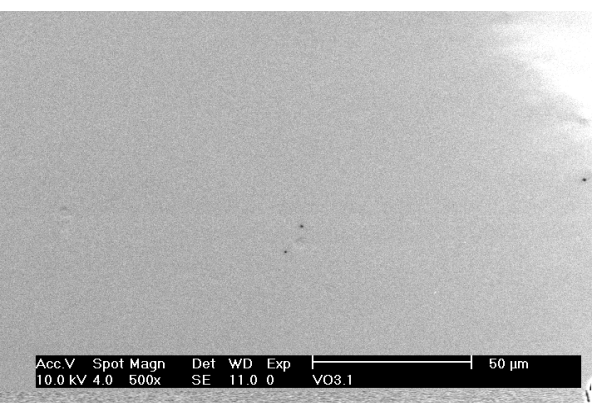

$\mathrm{C}$

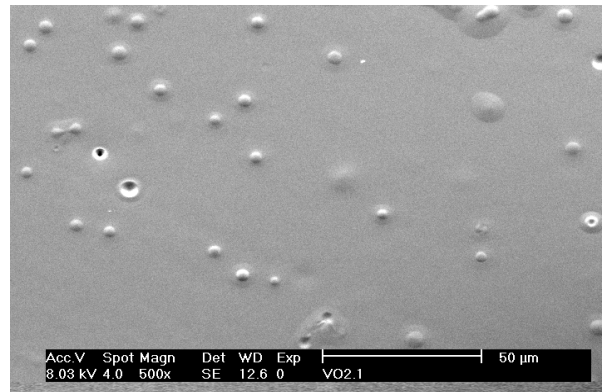

B

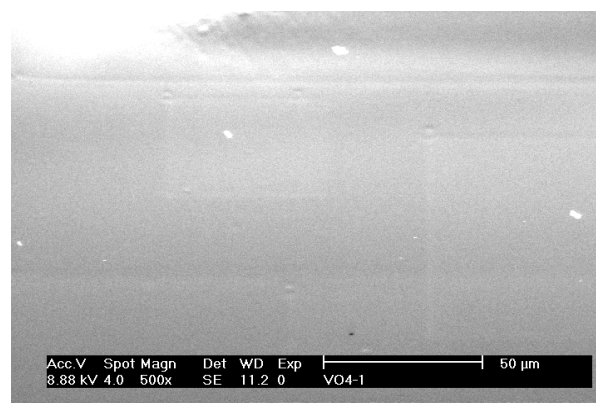

D

Figure 2. A. Film Layer of Single Application of Self-processing varnish; B. Film Layer of Twice Application of Self-processing varnish; C. Film Layer of three times Application of Self-processing varnish; D. Film Layer of four times Application of Self-processing varnish

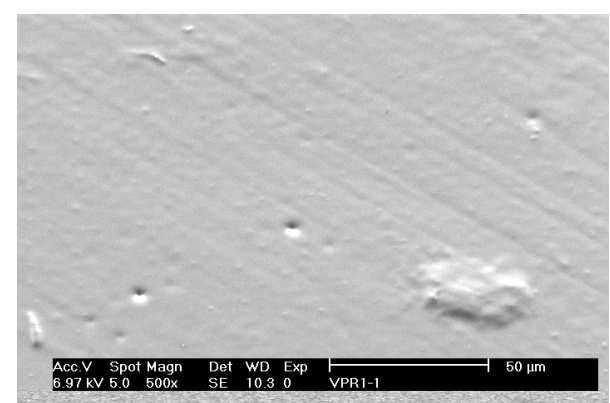

A

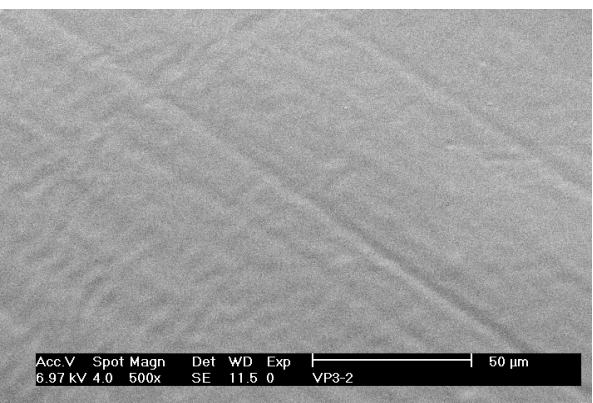

$C$

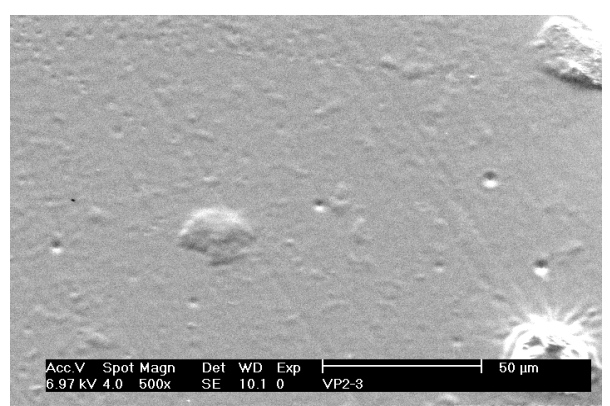

B

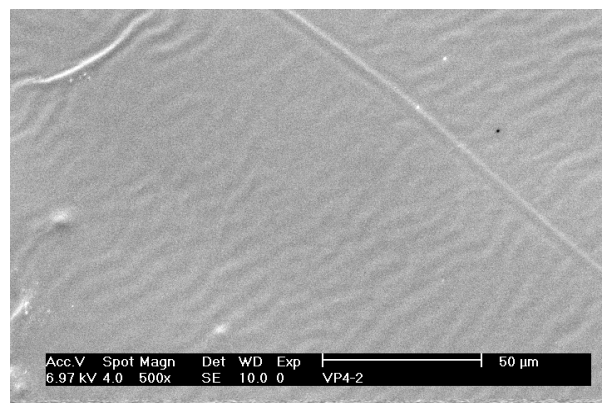

D

Figure 3. A. Film Layer of Single Application of Fabricated (GC-Fuji) Varnish; B. Film Layer of Twice Application of Fabricated (GC-Fuji) Varnish; C. Film Layer of Three times Application of Fabricated (GC-Fuji) Varnish; D. Film Layer of Four times Application of Fabricated (GC-Fuji) Varnish

in an almost invisible, very thin film layer. This occurred due to the fact that copal powder did not dissolve completely in $70 \%$ alcohol. The alcohol concentration was then increased to $95 \%$, so that all copper powder was soluble and produced clearly visible film layer. Visually, the self-processed varnish film layer with 95\% alcohol solvent had a similar film layer generated by factory-made varnish, but the time required for the film layer to dry completely on the selfprocessed varnish was longer than that of the manufactured varnish. To speed up the time, 
chloroform was added to the preparation resulting in formation of film layer with sufficient thickness, visually visible, and faster time required for the film coating to dry completely.

The porosity of the self-processed varnish film layer with single application was noticeable and had larger size than the fabricated varnish. The self-processed varnish film layer with twice of application showed the presence of porosity as well as bubble form. Bubble may arise due to two things: the time in between two layer applications was too fast or the varnish solution was too thick. ${ }^{21} \mathrm{~A}$ thick varnish solution was caused by evaporation of the solvent contained in the varnish preparation. This problem could be solved by diluting the varnish preparation using the same solvent as the solvent contained in the preparation. ${ }^{22}$

The film layer of varnish on the first application protected $55 \%$ of the tooth surface, while the second layer of the film protected 80 $85 \%$ of the tooth surface. ${ }^{1}$ Based on the fact, it was expected in the third and subsequent layers, the film layer of varnish can protect the surface of the tooth perfectly. This is in line with the results of the research that showed the self-processed varnish film layer with three and four times of application showed no porosity. Similar results were obtained in fabricated varnish film layer with the same amount of application.

It could be obtained from the SEM result that blisters around the formed porosity were visible. According to Morrel and Waele ${ }^{21}$, blisters on the film layer of varnish were caused by trapped solvents that evaporated and the heat was received by the coating. These blisters may occur because SEM generated heat that promote the formation of blisters.

Uneven film layers affected porosity. To control the occurrence of porosity, it was necessary to apply the varnish with a thin flat layer. In addition, it took three times of application to obtain a film layer that was feasibly cover the entire surface of the tooth so that the purpose of using the varnish as sealant could be achieved.

\section{CONCLUSION}

There is a difference in the percentage of porosity formed on the self-processed varnish based on copal and alcohol film layer with the factorymade varnish. The porosity percentage of the self- processed varnish film layer is greater than that of the manufactured varnish both on singular and twice of application, although this difference is not statistically significant. There is influence of the application frequency to the porosity formed in the varnish film layer in either selfprocessed or manufactured groups. Meanwhile in the application itself, varnish requires three times of application with a thin and even layer. Further study on the effective self-processed varnish ingredients that produce minimum porosity of film layer are to be conducted in the future. Given the amount of energy that SEM device spend during observation and picture taking, the use of other observation tools other than SEM is worth to be considered in order to produce better picture results and allow observations on larger amount of samples.

\section{REFERENCES}

1. Roberson TM, Heymann HO, Swift EJ. Sturdevant's: art and science of operative dentistry. $4^{\text {th }}$ ed. St. Louis: Mosby Co.; 2002. p. 170-3.

2. Hernandez P, Barcelo F, Palma M. Thickness of copal varnish film. Mexican Division 1988 Meeting. 1988. [cited 2008 Nov 14] Available from: http://jdr.iadrjournals.org/cgi/reprint /68/4/695.pdf.

3. Ferracane JL. Materials in dentistry: principles and aplications. $2^{\text {nd }}$ ed. Philadelphia: Lippincott Williams and Wilkins; 2001. p. 62.

4. Craig RG, Powers JM. Restorative dental materials. $11^{\text {th }}$ ed. St. Louis: Mosby; 2002. p. 502-3.

5. Anderson JN. Applied dental materials. $5^{\text {th }}$ ed. London: Blackwell Scientific Publ; 1976. p. 353-4.

6. Baum L, Phillips RW, Lund MR. Textbook of operative dentistry. $2^{\text {nd }}$ ed. Philadelphia: W.B. Saunders Co.; 1985. p. 126-9.

7. Gladwin M, Bagby M. Clinical aspects of dental materials. Philadelphia: Lippincott Williams \& Wilkins; 2000. p. 84.

8. Manappallil JJ. Basic dental materials. $2^{\text {nd }} e d$. India: Jaypee Brother Medical Publisher Ltd. 2003. p. 263-6. 
9. Food and Agriculture Organization of the United Nations. Hard resins. 1995. [cited 2009 Nov 14] Available from: http://www.fao.org/ docrep/v9236e/V9236e07.htm

10. Waluyo TK, Dalian E, Edriana E. Percobaan pembuatan pernis dari kopal. Bogor: Forestry Research and Development Board. 2004 [cited 2009 Nov 10] Available from: http: / / www. forda-mof.org/informasi. asp?kategoriid $=45 \&$ rootid $=13$ \&page $=5$

11. Parry EJ. Gums and resin. University of California Libraries. 1918 [cited 2009 Nov 14] Available from: http://www.archive.org/ details/gumsresinstheiro00parrrich

12. Grossman LI. Dental formulas and aids to dental practice. Philadelphia: Lea and Febiger; 1952. p. 14-6.

13. Anusavice KJ. Phillip's science of dental materials. $11^{\text {th }}$ ed. Missouri: Saunders; 2003. p. 439.

14. O’Brien WJ. 1989. Dental materials: properties and selection. Chicago: Quintessence books; 1989. p. 203-8.

15. Ministry of Forestry. Hasil hutan non kayu. 2008. [2008 Nov 14] Available from: http:// www.dephut.go.id/informasi/propinsi/
SUMSEL/hhnk.html.

16. Skinner EW, Phillips RW. The Science of Dental materials. $9^{\text {th }}$ ed. Philadelphia: W.B. Saunders Co.; 2001. p. 239-40.

17. Hatrick CD, Eakle WS, Bird WF. Dental materials: clinicals aplications for dental assistants and dental hygienists. St. Louis: Saunders; 2003. p. 173-4.

18. Ansel HC. Pengantar bentuk sediaan farmasi. $4^{\text {th }}$ ed. Jakarta: Universitas Indonesia; 1989. p. 313.

19. Clark J. Kegunaan alkohol. 2009. [2009 Apr 3] Available from: http://www.chem-is-try. org/materi_kimia/sifat_senyawa_organik/ alkohol1/kegunaan_alkohol/

20. Kennedy DB, Roberts JF, Curzon MEJ. Paediatric operative dentistry. $4^{\text {th }}$ ed. British: Wright; 1996. p. 130.

21. Morrel RS, Waele AD. Rubber resins paints and varnishes. London: Bailliere Tindall and Cox; 1921. [2009 Mar 7] Available from: http: / / www.archive.org/stream/rubber resinspain00morruoft.

22. Craig RG, O'Brien WJ, Powers JM. Dental materials: properties and manipulation. $6^{\text {th }}$ ed. St. Louis: Mosby; 1996. p. 128. 